\title{
Integrated A Variable Frequency Drive for a Diesel-Generating Set using the Genset-Synchro Concept
}

\author{
Mohamad Issa $^{1}$, Karim Ait-Yahia ${ }^{1}$ \\ ${ }^{1}$ Department of Applied Sciences, \\ Institut Maritime du Québec, Rimouski, G5L 4B4, \\ Canada
}

\author{
Richard Lepage $^{2}$, Hussein Ibrahim ${ }^{2}$, Adrian Ilinca ${ }^{2}$ \\ ${ }^{2}$ Department of Mathematics, \\ Informatics and Engineering, Université du Québec à \\ Rimouski, Rimouski, G5L 3A1, Canada
}

\author{
Mazen Ghandour ${ }^{3}$ \\ ${ }^{3}$ Faculty of Engineering, \\ Lebanese University, Beirut, ULFG1, \\ Lebanon
}

\begin{abstract}
This paper examines the feasibility of implementing a variable frequency drive based on real-time control of the stator speed for a standby diesel generating-set using Genset-Synchro technology. The controller algorithms are designed using the Code Composer Studio version 8.0 software in $\mathrm{C}$ code, which can be downloaded to the digital signal controller TMS320F28335 from Texas Instruments in real-time. The paper shows results for the compensator motor that drives the stator speed to maintain the voltage and frequency at the output fixed. The results show the possibility to meet the performance class criteria of ISO 8528 part 5 G2 when diesel generators are equipped with Genset-Synchro technology.
\end{abstract}

Keywords - Variable Diesel Generator, Genset-Synchro, EoSynchro, Real-Time Control, ISO 8528, Variable Frequency Drive.

\section{INTRODUCTION}

A conventional diesel generator (DG) consists of an engine connected directly to a synchronous alternator to produce electricity. Since the electricity produced must be at fixed frequency, normally $50 \mathrm{~Hz}$ or $60 \mathrm{~Hz}$, the engine must rotate at a constant speed typically $1500 \mathrm{rpm}$ for $50 \mathrm{~Hz}$ or $1800 \mathrm{rpm}$ for $60 \mathrm{~Hz}$, no matter what the power demand is. One solution to save fuel in a diesel generator is to enable the engine to operate at variable speeds in direct relation to the electrical load demand [1]. The Genset-Synchro concept is especially, based on a completely different point of view of the known and preconceived ideas of what should be the standard alternator constitution. The innovation of the concept stems from the reality that the structure containing stator windings is mounted on roller bearings enabling its free rotation around the rotor axis, thereby preventing the stator structure from being static [2-4]. In order to ensure the rotation speed of the stator, an electric motor (compensator) installed directly on the alternator drives the rotation of the stator through a belt and pulley, Figure 1 [5].

By allowing the free rotation of the stator, the diesel generator set (DGS) is switched to operate at variable speed [2-5]. The synchronous speed of this alternator can remain constant through three different ways:
- Rotor speed only;

- Stator speed only;

- Both speeds simultaneously.

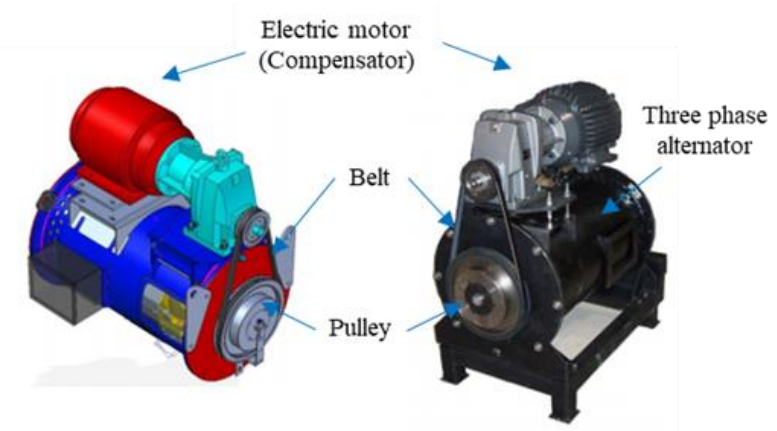

Figure 1. Illustration of the concept and main components of the GensetSynchro technology

Previous work by the authors [4-8] has shown a potential reduction in fuel and greenhouse gases (up to 15\%) when a diesel generator is equipped by a Genset-Synchro alternator with a 300-rpm fixed stator speed. However, in situations where a diesel-generating set is required to operate in standalone mode, the absence of an automated circuit to control the stator speed according to the applied load, can greatly affect the power quality (to maintain constant voltage and frequency with changing load) at the output of the generator.

As the ultimate objective of this work is integrate total control of a diesel-generating set equipped by a rotational stator alternator. This paper examines the development and implementation of a variable frequency drive to govern the stator speed of a $500 \mathrm{~kW}$ alternator using a $75 \mathrm{~kW}$ electric compensator motor. The paper shows results for the proposed controller in a basic form. The international standard ISO 8528 Part 5 is considered in order to evaluate the performance class of diesel-generating set using rotational stator in relation to voltage and frequency regulation [9]. This 
standard provides a guide to the performance of an improved automatic control stator speed.

Testing was conducted at Genset-Synchro enterprise in collaboration with the University of Quebec at Rimouski on a 700KVA generating set with a 6-cylinder turbo aspirated electronic engine using resistive load.

\section{DIGITAL SIGNAL PROCESSORS (DSP) BASED INDUCTION MOTOR CONTROL}

Digital Signal Processors (DSP) provide high speed, high resolution and better induction motor control under different load circumstances.

The DSP-based induction motor drive system is composed of hardware systems such as induction motor, inverter, rectifier, eddy current load configuration, sensing unit DSP board and torque indicator. By comparing the modulated signal and carrier signal as shown in Figure 2, the pulse with modulation (PWM) signal is generated.

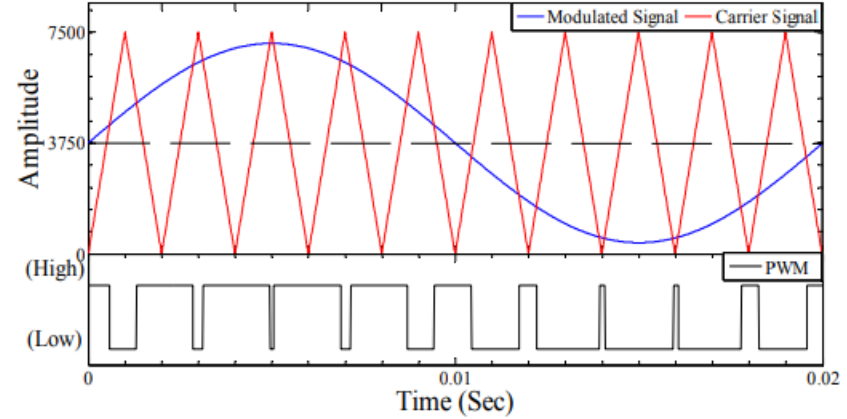

Figure 2. Illustration of the PWM generation by comparison of modulation signal with carrier signal.

For the creation of required SPWM pulse, the sinusoidal signal with frequency ' $F_{m}$ ' and voltage ' $V_{m}$ ' is compared with high frequency triangular carrier with frequency ' $F_{c}$ ' and voltage ' $V_{c}$ ' to operate gate drive for voltage source inverter. The variation in inverter output voltage amplitude and frequency relies entirely on the modulated sinusoidal signal because the carrier triangular signal has fix amplitude and constant frequency. The carrier frequency signal is used to determine the frequency of the PWM switching. The power quality parameter (harmonics, transients, active and reactive power, RMS voltage-current) of output voltage of inverter is depends on switching frequency of PWM signal. In other words, we can say that the modulated signal is used to regulate the speed and torque of the engine while the signal of the carrier is concerned with frequency switching problems and power quality. According to Figure 2, the pulse width is varying according to modulated signal and frequency is varies according to carrier signal. Dead bands were injected into the perfect PWM waveform for realistic security concerns. The dead band is provided by averting conductive overlap to safeguard the IGBTs at the moment of switching. PWM signals are produced according to the algorithm of speed feedback and control. The actual speed of the compensator motor is sensed by quadrature encoder pulse (QEP) speed detector. The voltage/frequency control is used in this suggested scheme, so the compensator motor speed is governed by the stator voltage and frequency in such a way that the air gup flux at the required value is constantly maintained at the steady state.

\section{PLATFORM DETAILS}

The hardware/software platform employed is the new generation digital signal processor TMS320F28335 with a high sampling rate to make it possible that it achieves good dynamics [10]. The algorithm is designed using MATLAB/SIMULINK and converted into $\mathrm{C}$ language using Code Composer Studio Version 8.0 environment. The sine pulse width modulation (SPWM) control algorithm is pro-posed for 3 phase three-leg IGBT voltage source inverter.

\section{A. The PC Software Requirements}

The various software packages and toolboxes that are required to build system models and compile real-time executable $\mathrm{C}$ code are:

- MathWorks MATLAB R2017B

- MathWorks Simulink R2017B

- Code Composer Studio environnement Version 8.0

- Microsoft Visual Studio 2019

\section{B. The PC Hardware Requirements}

Figure 3 is an illustration of the actual test-bed hardware layout. The hardware requirements are as follows:

- Host desktop PC: used to develop the PID controller program using Simulink and then to auto-compile the model into $\mathrm{C}$ source code, which can be downloaded to the DSP TMSF320F28335

- DSP TMS320F28335 from Texas Instruments: Implementing the controller to manage the PWM that in turn enables the IGBT gate drivers

- Three full bridge IGBT Gate drivers: to provide total control of the power supply of the compensator motor

- $\quad 100 \mathrm{HP}$ electric compensator motor, 208V, 3 phases

IV. KEEPING THE VOLTAGE AND FREQUENCY FIXED

The role of a governor for a diesel-generating set when operated in isolation from the mains utility supply is to maintain the nominal frequency of the alternator terminal voltage. This is achieved by controlling the fuel quantity delivered to the engine combustion chamber. The international standard ISO 8528 Part 5 is used by diesel engine and generating set manufacturers to classify the performance class of a particular generating set in relation to voltage and frequency regulation [11]. 


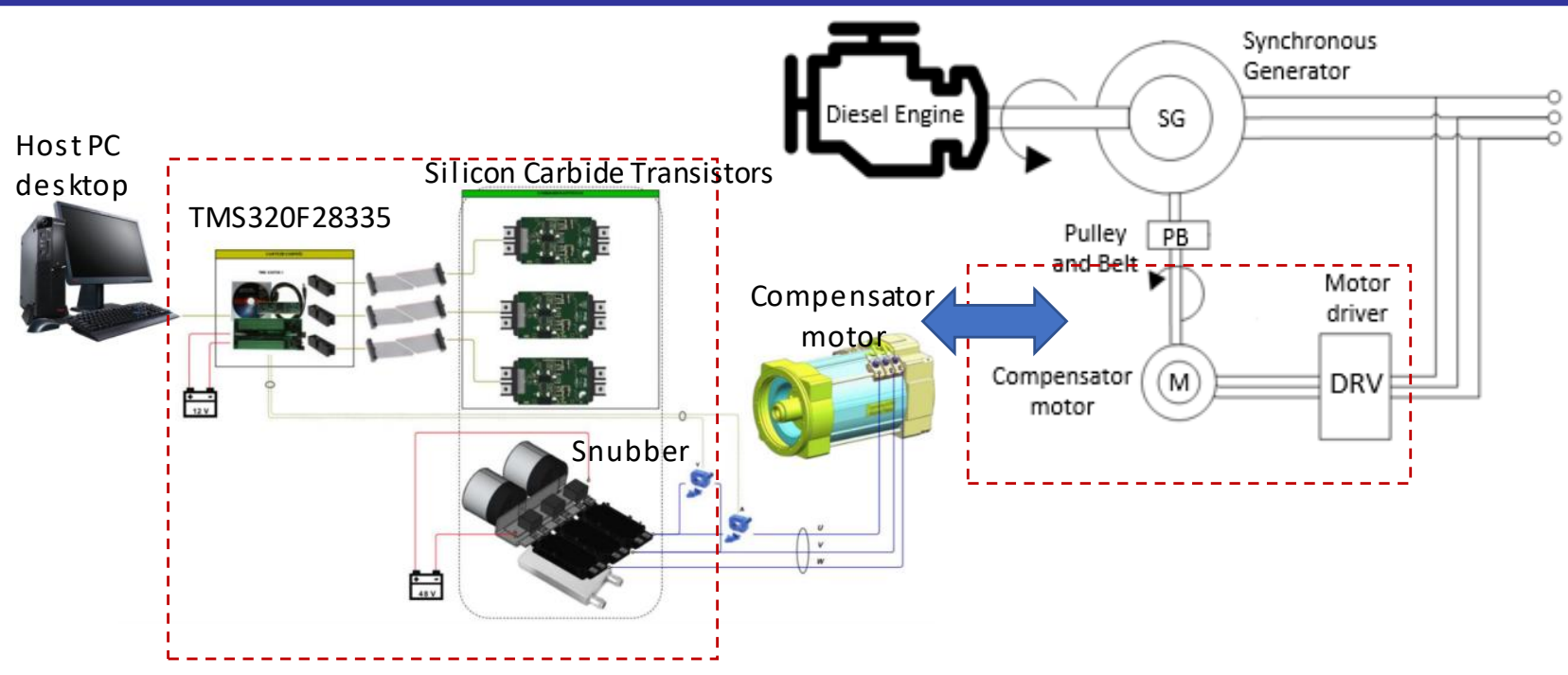

Figure 3. An illustration of the test bed-layout

To achieve a fuel savings, Genset-Synchro technology relies on reducing the diesel engine speed (ranging from 1800 rpm to $1500 \mathrm{rpm}$ ) and compensates by the rotation of the stator in the opposite direction of the rotor (300rpm) to keep the frequency $(60 \mathrm{~Hz})$ and voltage fixed. On a previous work [4-8], the technology has shown significant fuel savings (up to $15 \%)$ on different diesel generators $(75 \mathrm{~kW}, 500 \mathrm{~kW}$ and $600 \mathrm{~kW})$ under several stable loads. To date, no stator speed control system has been developed and the speed adjustment is done manually at the start-up of the generator. For this, we propose a control system based on the use of a frequency inverter to drive the compensating motor which, in turn, ensures the rotation of the stator. The control algorithm used the engine speed error, change in engine speed error, and the three-phase rectified average terminal voltage value to control the stator speed controlled by the compensator motor. Figure 4 shows a representation of the control strategy used to govern the speed of the compensator motor which, in turn, causes the stator to rotate. The engine information accessible on the engine control module (ECM) such as engine speed, required fuel, etc. are retrieved by the manufacturer and programmed in the DSP controller.

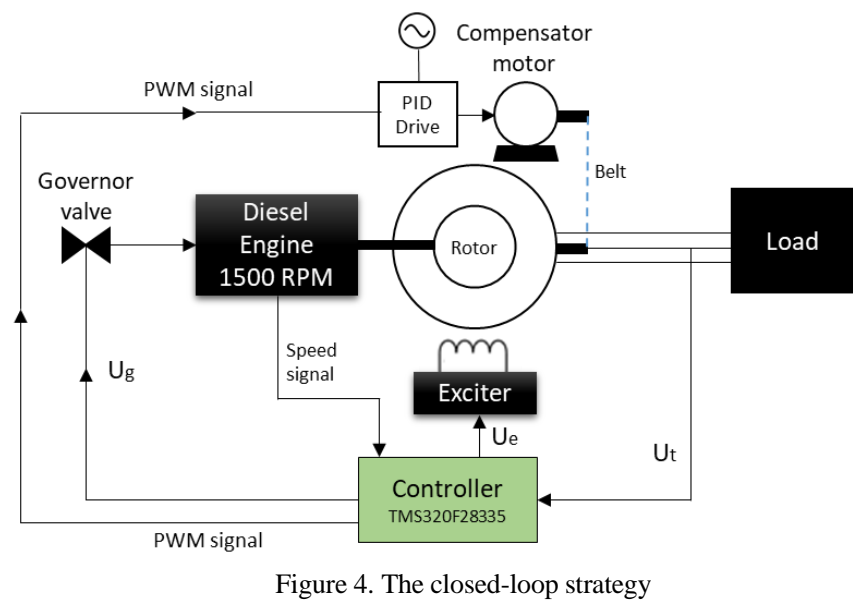

The engine speed is measured as follows:

- A magnetic pick-up is used to produce a waveform of sinusoidal voltage

- This waveform is converted into a square wave by a buffered Schmitt trigger circuit

- A DSP counter function is integrated to calculate the period of the square wave

The measured engine speed is used to determine the engine speed error and change in engine speed error. The additional input to the DSP controller is a three-phase rectified terminal voltage value which each phase voltage is stepped down to a voltage within the range of the analogue input on the DSP TMSF320F28335 card then sampled by the analogue input. The rectification and averaging of the three-phase voltage are conducted within the DSP con-troller card. The speed error change in speed error, and voltage error values can then be processed by the con-trol algorithm to calculate a new stator speed when the load changes.

\section{A. Why use voltage?}

Voltage was chosen as an additional input to the compensator motor control scheme, as during resistive load disturbances both diesel engine speed and voltage are affected. Speed error- This caused due to real power load disturbances. For example, a resistive load applied to the alternator demands extra electrical energy. However, there will be a shortfall in the Kinetic energy supplied by the diesel engine due to insufficient fuel delivered to the combustion chamber. This causes the engine to decelerate. The inertia of the generating unit determines the deceleration.

Voltage error- this is introduced due to several factors when a complex load is applied to the alternator.

- Armature reaction: this is due to the need for the synchronous alternator to increase the rotor field current $\left(\mathrm{I}_{\mathrm{f}}\right)$ to meet the increase in demanded main field $\left(\mathrm{F}_{\mathrm{f}}\right)$. This is shown in Figure 5.

The main field MMF (Ff) depends on several factors. Equation (1) shows the relationship between Ff to the field current (If) and the number of rotor turns $\mathrm{Nf}$. 


$$
\mathrm{Ff}=\mathrm{Nf} \text { If }(\mathrm{AT})
$$

The rotor angle $\delta$ is regarded as the real power load angle and is the angle between the generated EMF phasor E, which is induced by the main field $\operatorname{MMF}\left(\mathrm{F}_{\mathrm{f}}\right)$, and the terminal voltage phasor $\mathrm{V}$, which is produced due to the resultant MMF $F_{r}$. The $F_{a r}$ MMF is termed the armature reaction MMF.

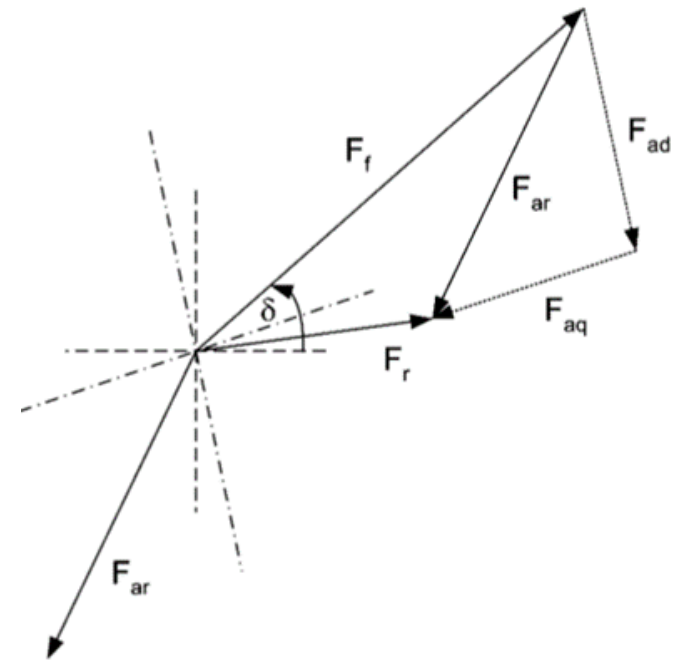

Figure 5. Representation of the space vector diagram of the MMF fields generated by the generated current in the stator in a salient pole alternator.

- Internal voltage drops within the alternator due to the relationship between the output current and the internal synchronous reactance of the alternator. The response time of the engine speed is therefore dependent on the inertia of the engine, flywheel, and alternator rotor combination, while the voltage response is dependent on the electromagnetic characteristics of the alternator.

\section{SYSTEM DESIGN AND SIMULATION}

The simulation is designed according to hardware specification and control algorithm. The V/F-SPWM model is executed progressively equipment setup utilizing DSP MATLAB interface. The Simulink developed model (Figure 6) consists to simulate the required time for the compensator motor to ensure a stator speed of $300 \mathrm{rpm}$ at the start-up with a $50 \%$ resistive load and $350 \mathrm{rpm}$ (passing from $300 \mathrm{rpm}$ to $350 \mathrm{rpm}$ ) when applying a load higher than 50\%. According to Figure 7 , the required time at the start-up for the compensator motor to ensure a stator speed of $300 \mathrm{rpm}$ is 3.6 sec while applying a load higher than $50 \%$, the pulley ratio will change from 1:6 to $1: 5.14$ and the response time for adjusting the stator speed to $350 \mathrm{rpm}$ is evaluated to $800 \mathrm{~ms}$.

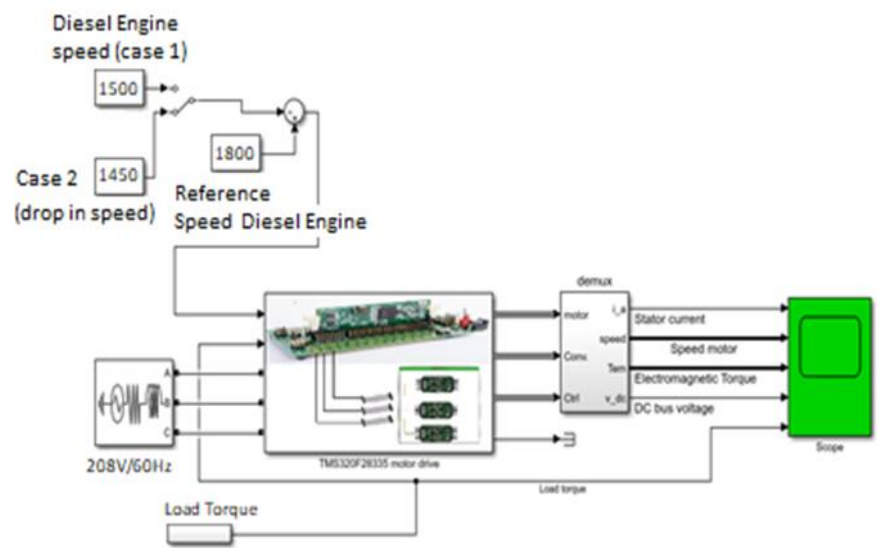

Figure 6. The Simulink developed model

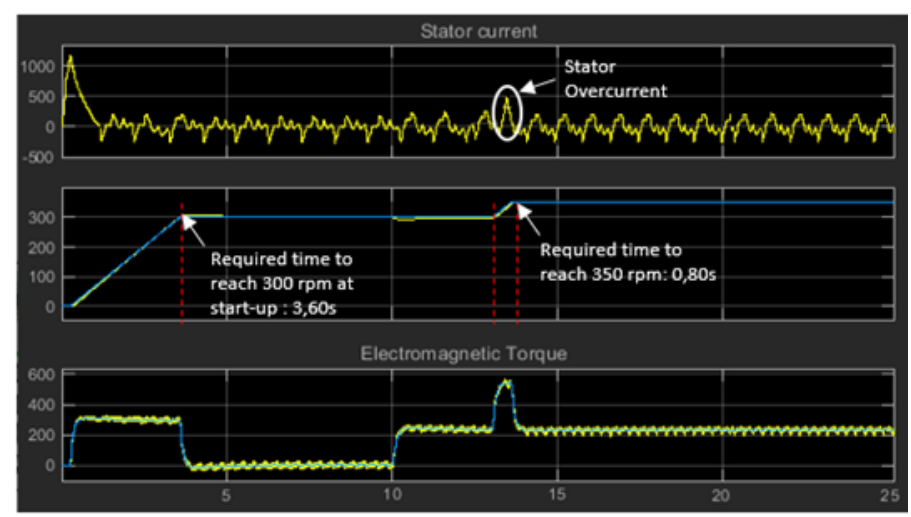

Figure 7. Simulation results of proposed model

The real-time speed of compensator motor is sense by QEP detector which gives pulses of $12.8 \mathrm{kHz}$ at $1800 \mathrm{rpm}$. The quadrature encoder pulse (QEP) sensor gives two quadrature signals, i.e. QEPA and QEPB. The real time QEP encoder output has been shown in Figure 8. The phase angle between QEPA and QEPB is approximately $90^{\circ}$ and signal frequency is approximately $12.02 \mathrm{kHz}$, which indicate $1700 \mathrm{rpm}$. The frequency of QEPA signal is capture by eCAP module (Actual speed) as capture count. The frequency of QEP sensor and DSP clock must be synchronising for speed measurement. The error between set and actual speed is given to the speed proportional integral (PI) controller. The PI controller is tune by trial and check method. The MATLAB/Simulink model of speed PI controller/regulator is shown in Figure 9.

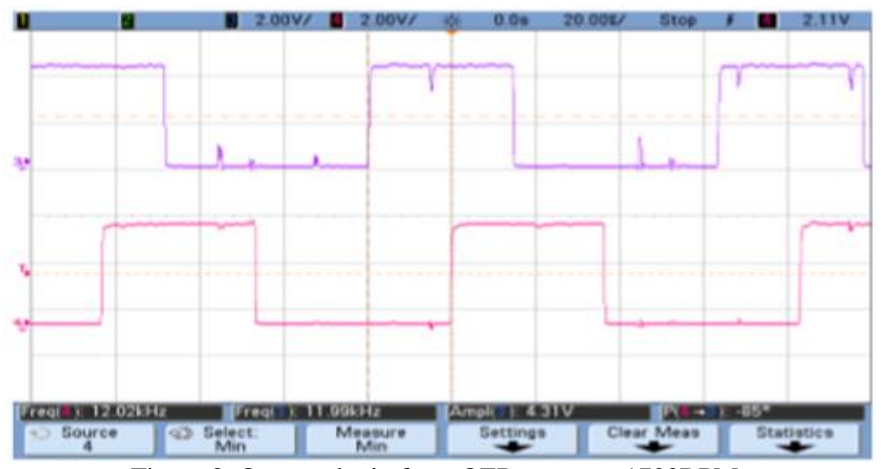

Figure 8. Output obtain from QEP sensor at 1700RPM 


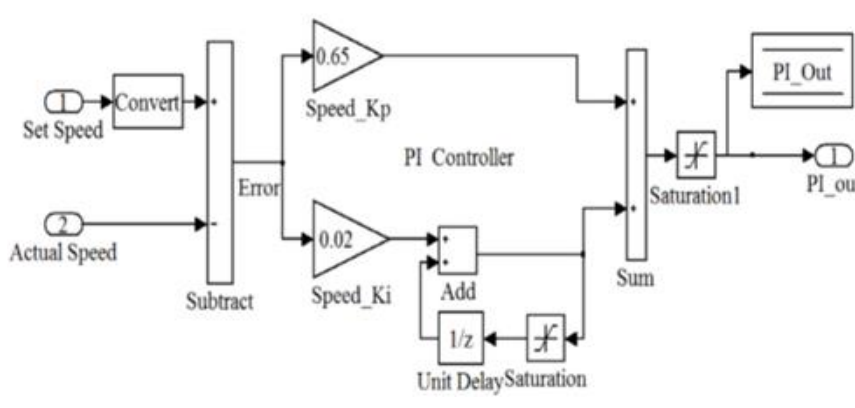

Figure 9. Illustration of the MATLAB/Simulink Model of PI-Controller

The output of PI controller (PI_out) is used to generate desired sinusoidal signal. The control model is design in MATLAB/Simulink for generation of desired modulated sinusoidal signal. The all possible sample of sinusoidal signal is store in memory as look up table. The frequency and amplitude of sinusoidal signal is control by frequency and amplitude modulation index (MI) respectively. The frequency modulation index of sinusoidal signal is derived by given derivation.

Specified frequency of carrier signal $(\mathrm{Fc})=10 \mathrm{KHz}$

Rated frequency of sinusoidal signal $(\mathrm{Fm})=60 \mathrm{~Hz}$

Required number of sample $(n)=F_{C} / F_{m}=10000 / 60=166$

Available sample by DSP $=2^{16}=65536$

Sample step count $=$ Available sample $/$ Required sample $=$ $65536 / 166=395$

Frequency step count $=$ Max. sample set count/Rated speed of motor $=395 / 1800=0.219$

So, frequency Modulation Index $\left(\mathrm{MI}_{\mathrm{f}}\right)=0.219$

The amplitude modulation index of sinusoidal signal is derived by given derivation.

Available maximum amplitude of sinusoidal signal $=3750$

Required maximum amplitude of sinusoidal signal $=90 \%$ of available maximum amplitude of sinusoidal signal

Required maximum amplitude of sinusoidal signal = $90 * 3750 / 100=3375$

Amplitude step count $=$ Required max. amplitude/rated speed of compensator motor $=3375 / 1800=1.87$

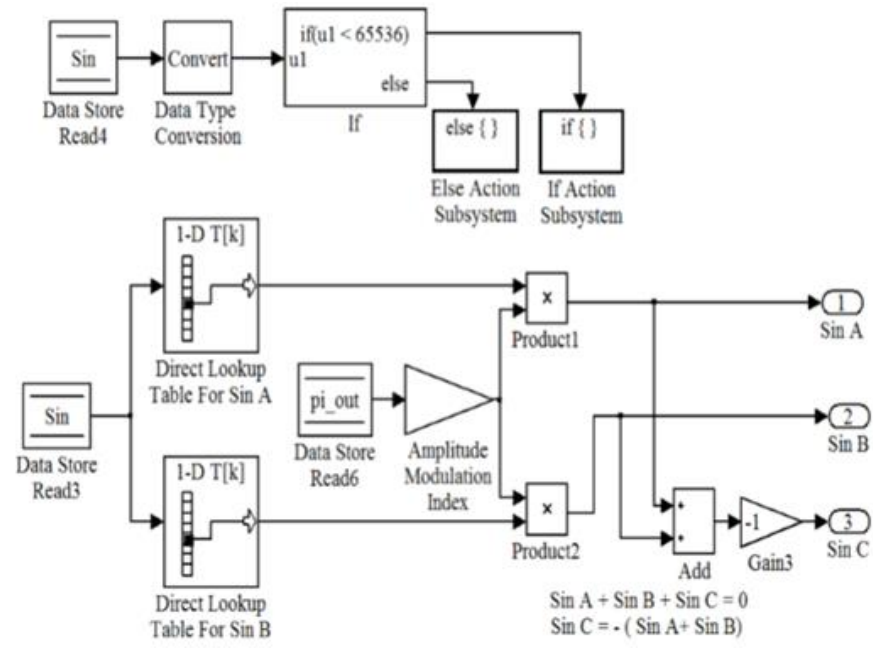

Figure 10. Illustration of the MATLAB/Simulink Model for sinusoidal signal generation
According to above derivation all available (65536) sample of one cycle of sin wave with zero phase and $120^{\circ}$ phase are store in lookup table ' $\mathrm{A}$ ' and lookup table ' $\mathrm{B}$ ' respectively. The output value of lookup table is depending on predefined sin variable. The sin variable is depending on PI_out and frequency modulation index $\left(\mathrm{MI}_{\mathrm{f}}\right)$. So according to PI_out value sin variable varies from 0 to 65536 and generates variable frequency sinusoidal signal from lookup table. The desired amplitude of sinusoidal signal is acquired by PI_out and amplitude modulation index. Figure 11 shows that 3 sinusoidal signal each shifted by $120^{\circ}$ phase is generated by above model. The signal is used to generate desired PWM Sequence.

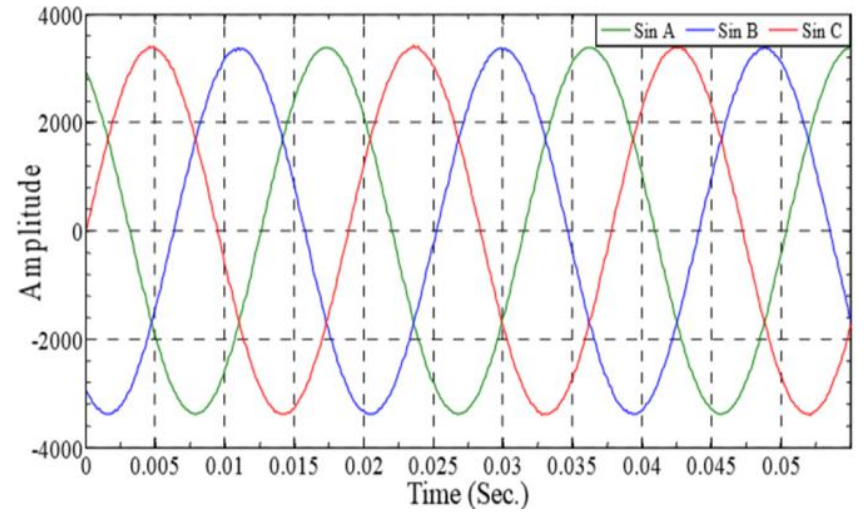

Figure 11. Illustration of the 3-phase sinusoidal signal

The high frequency $(10 \mathrm{KHz})$ triangular carrier signal is generated by ePWM module by up-down count mode. The nature of carrier signal is unidirectional and sinusoidal signal is bidirectional, so they are not intersecting in negative half cycle of sinusoidal signal. The creation of the PWM waveform is accomplished in the practical implementation of the system by comparing the value of a time-base counter (TBCTR) (the carrier signal) with the instantaneous value of the sinusoidal signal. Sinusoidal signal instantaneous value is stored in a counter comparison register (CMPA). When the time-base counter (TBCTR) in up count mode is equal to CMPA, it sets the ePWMA register and the down count mode is clear. To obtain the required PWM frequency, time-base period register (TBPRD) is needed to be determined. PWM frequency $\left(\mathrm{f}_{\mathrm{PWM}}\right)$ can be written as.

$$
\text { TBPRD }=1 / 2 * f_{\text {SYSCLKOUT }} / f_{\text {PWM }} * \text { CLKDIV } * \text { HSPCLKDIV }
$$

The designated PWM frequency (fPWM) is $10 \mathrm{KHz}$ according to the project design specification and the DSP setup and the clock frequency of system (fSYSCLKOUT) of the DSP F28335 is $150 \mathrm{MHz}$. CLKDIV and HSPCLKDIV are selected to be 1 . The value set in the time-base register (TBPRD) can be obtained directly on the basis of equation (6).

TBPRD $=1 / 2 * 150 * 10^{6} / 10^{*} 10^{3 *} 1 * 1=(7500)_{10}=(1 \mathrm{D} 4 \mathrm{C})_{16}$ The high frequency complimentary PWM drive signal ePWMA and ePWMB are illustrated in Figure 12. 


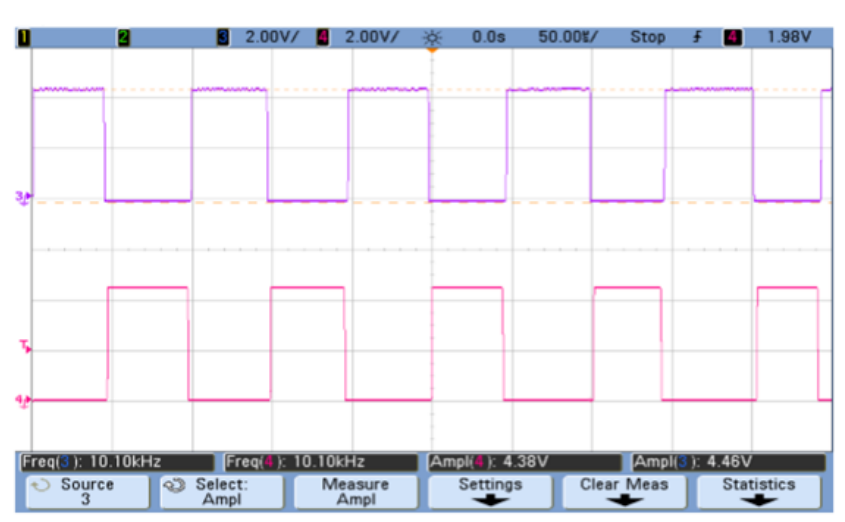

Figure 12. PWM pulses signal generated by ePWMA and ePWMB module.

According to Figure 13, the amplitude of drive signal was found to be 4.45 Volt with a frequency $10 \mathrm{kHz}$.

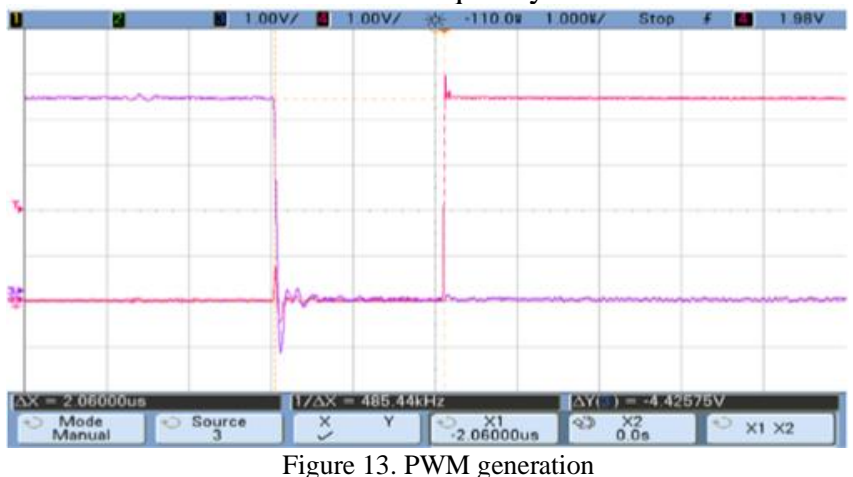

\section{TEST RESULTS}

The inverter's DC connection voltage is first set for protection and safety purposes by autotransformer at $300 \mathrm{~V}$, and then IGBTs are provided PWM. Table 1 demonstrates the suggested control method's V/F ratio at different speeds of the compensator motor, while Figure 14 illustrates the realtime line parameter measurement of the compensator motor using the power analyzer.

Table 1. Evaluation of V/F and stator speed at various speeds of the compensator motor.

\begin{tabular}{|c|c|c|c|c|}
\hline $\begin{array}{c}\text { Compensator } \\
\text { motor speed } \\
(\mathrm{rpm})\end{array}$ & Voltage (V) & $\begin{array}{c}\text { Frequency } \\
(\mathrm{Hz})\end{array}$ & $\begin{array}{c}\mathrm{V} / \mathrm{F} \\
\text { ratio }\end{array}$ & $\begin{array}{c}\text { Stator } \\
\text { speed (rpm) }\end{array}$ \\
\hline 500 & 70.2 & 18 & 3.90 & 83.3 \\
\hline 750 & 105.3 & 25.0 & 4.21 & 125 \\
\hline 900 & 144.2 & 37.0 & 3.89 & 150 \\
\hline 1200 & 170.0 & 44.9 & 3.78 & 200 \\
\hline 1500 & 194.6 & 50.0 & 3.89 & 250 \\
\hline 1750 & 207.9 & 60 & 3.46 & 291.6 \\
\hline
\end{tabular}

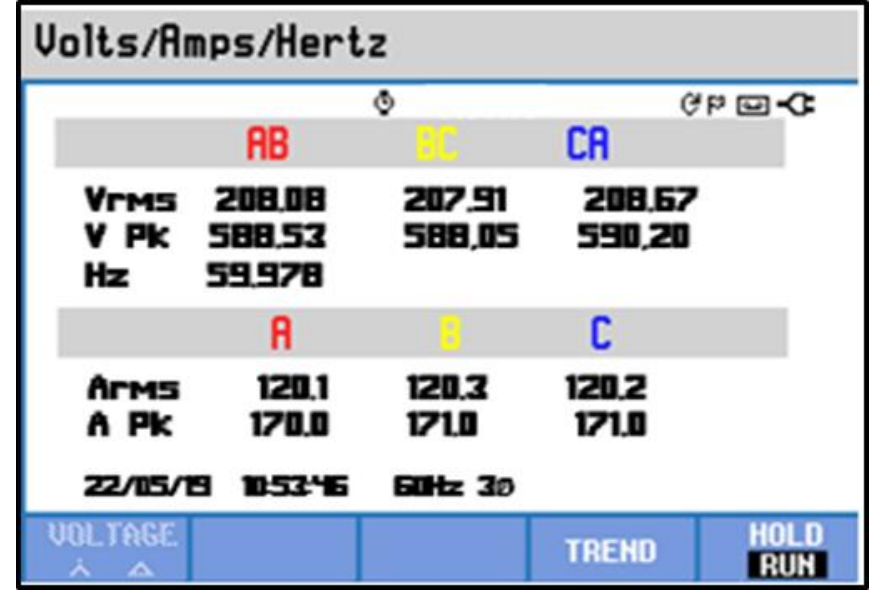

Figure 14. PWM pulses signal generated by ePWMA and ePWMB module.

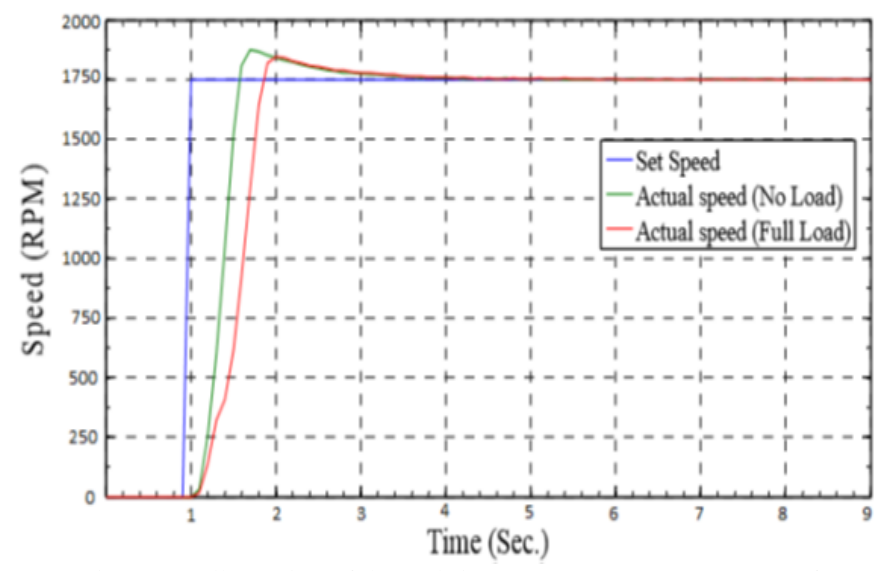

Figure 15. Illustration of the real-time step response (1750RPM of compensator motor)

The real time step and ramp response of motor speed at no load and full load are shown in Figure 15. The Step and ramp set commend is given by GPIO switch on DSP board. The real time current of the compensator motor is sense by halleffect sensor and measured by DSP (using ADC module). All acquired data of DSP has been transmits to PC (MATLAB) using SCI module. Table 2 performs the time response analysis of the above results. The outcome demonstrates that there is excellent dynamic response to the motor's step response at no load and full load.

Table 2. Illustration of the time response analysis of speed step response (compensator motor)

\begin{tabular}{|c|c|c|c|c|c|}
\hline & $\begin{array}{c}\text { Delay } \\
\text { Time } \\
(\mathbf{s e c})\end{array}$ & $\begin{array}{c}\text { Rise } \\
\text { Time } \\
(\mathbf{s e c})\end{array}$ & $\begin{array}{c}\text { Peak } \\
\text { Time } \\
(\mathbf{s e c})\end{array}$ & $\begin{array}{c}\text { Settling } \\
\text { Time } \\
(\mathbf{s e c})\end{array}$ & $\begin{array}{c}\text { Overshoot } \\
(\%)\end{array}$ \\
\hline No Load & 0.41 & 0.30 & 0.7 & 2.4 & 7.07 \\
\hline $\begin{array}{c}\text { Full } \\
\text { Load }\end{array}$ & 0.63 & 0.47 & 1.0 & 2.5 & 5.57 \\
\hline
\end{tabular}



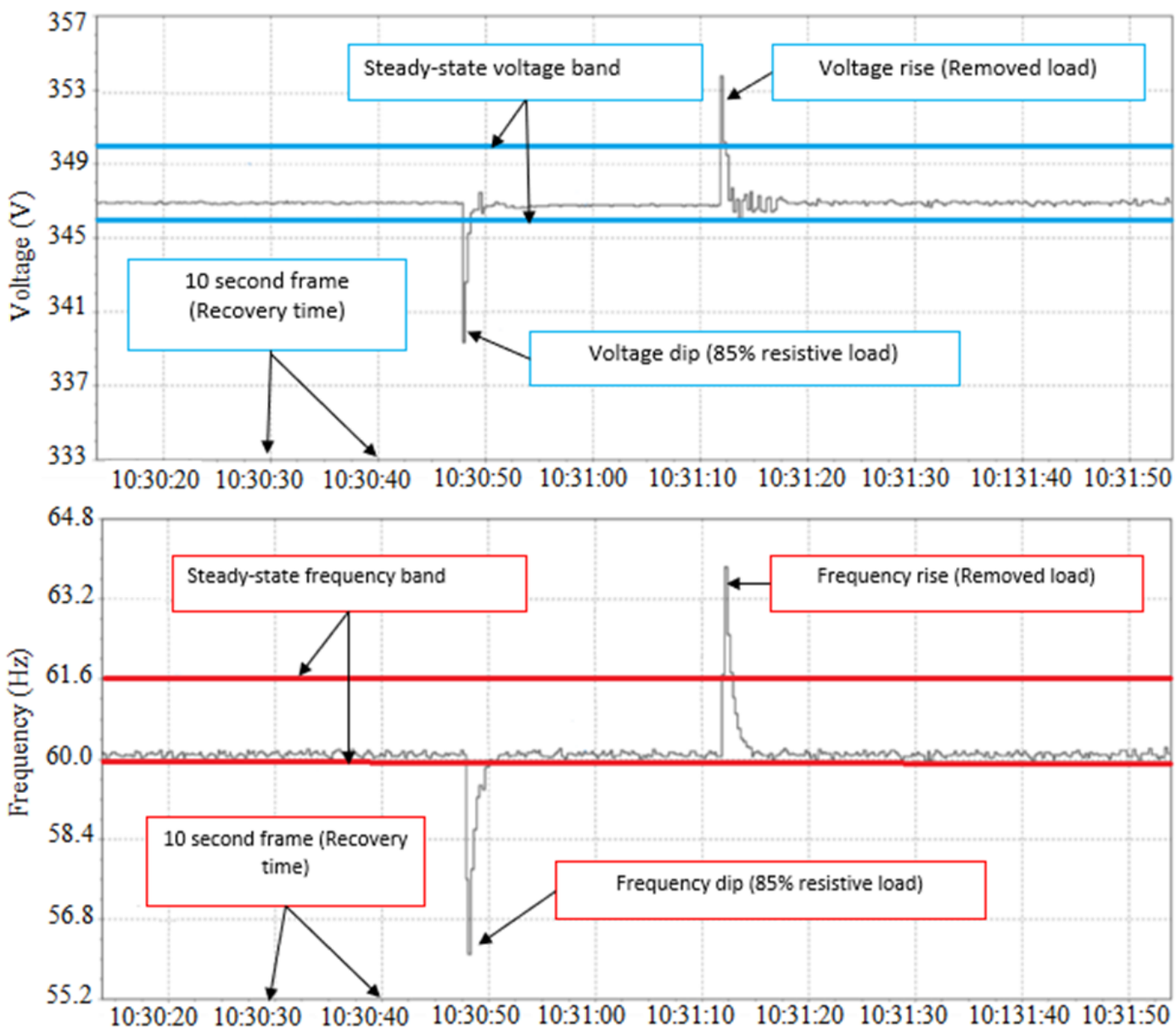

Figure 16. Illustration of the transient time responses of frequency and voltage qualifying the Genset-Synchro alternator to class $\mathrm{G} 2$ according to ISO 8528 standard

Finally, in order to evaluate the transient frequency and voltage times at the terminal output of the generator, we referred to ISO 8528-1:2018 standard. According to ISO 8528 standard, the Genset-Synchro set is qualified for class G2. Class G2 assumes that the maximum voltage dip is fixed at $-20 \%$ while the rise voltage is set at $+25 \%$ with a voltage retrieval moment of $6 \mathrm{sec}$. Concerning the frequency, the maximum frequency dip is set at $-10 \%$, while the maximum frequency rise is fixed at $+12 \%$ with a frequency recovery time of $5 \mathrm{sec}$. Figure 16 illustrates the transient voltage and the transient frequency responses when applying and removing an $85 \%$ resistive load.

\section{CONCLUSION}

An automatic controller to drives the stator speed for a diesel generator using the Genset-Synchro technology was developed and tested. The work conducted has initially proved successful in minimization the maximum speed deviation during load acceptance and meet the G2 performance classification in ISO 8528 Part 5 standard. The design and execution method of the digital signal processorbased MATLAB/Simulink model for compensator motor speed control has been very obviously described.
The sinusoidal PWM (SPWM) signals are produced using the dead band of the digital signal processor (TMS320F28335) for three phase operation and the signals are provided to the inverter module. In addition, the experimental findings indicate that DSP-based control systems have excellent efficiency, and greater control processor has made the engine velocity control more efficient than other standard methods.

In order to meet G3 performance classification in ISO 8528 part 5, the work must seek an appropriate control input, such as power or power factor, that can determine the actual power element of the complicated load, thus minimizing the influence of proportional voltage during low power factor load applications.

\section{REFERENCES}

[1] NAYAR, Chem. Innovative remote micro-grid systems. International Journal of Environment and Sustainability, 2012, vol. 1, no 3.

[2] Issa, M. , Fiset, J. , Ibrahim, H. and Ilinca, A. (2019) Eco-Friendly Selection of Diesel Generator Based on Genset-Synchro Technology for Off-Grid Remote Area Application in the North of Quebec. Energy and Power Engineering, 11, 232-247. doi: 10.4236/epe.2019.115015.

[3] Issa, M. , Ibrahim, H. , Lepage, R. and Ilinca, A. (2019) A Review and Comparison on Recent Optimization Methodologies for Diesel Engines and Diesel Power Generators. Journal of Power and Energy Engineering, 7, 31-56. doi: 10.4236/jpee.2019.76003.

[4] ISSA, Mohamad, FISET, Jean, MOBARRA, Mohammadjavad, et al. Optimizing the performance of a $500 \mathrm{~kW}$ Diesel Generator: Impact 
of the Eo-Synchro concept on fuel consumption and greenhouse gases. Powr Engineer, 2018, p. 23.

[5] MOBARRA, Mohammadjavad, FISET, Jean, et ILINCA, Adrian. Modeling and optimization of the energy production based on EoSynchro. Power Engineer, 2017, p. 3.

[6] Jean Fiset, Tony Durand, United States Patent \& Trademark Office Patent no. US8258641B2:Mechanical Regulation Of Electrical Frequency In An Electrical Generation System

[7] Fiset Jean, Canadian Intellectual Property Office -Patent no.2580360: Energy Transfer Apparatus

[8] Mobarra, M. , Issa, M. , Rezkallah, M. and Ilinca, A. (2019) Performance Optimization of Diesel Generators Using Permanent Magnet Synchronous Generator with Rotating Stator. Energy and Power Engineering, 11, 259-282. doi: 10.4236/epe.2019.117017

[9] ISO 8528. https://www.iso.org/fr/standard/68539.html

[10] DSP. http://www.ti.com/lit/ds/symlink/tms320f28335.pdf

[11] McGowan, D. J., Morrow, D. J., \& Fox, B. (2006). Integrated governor control for a diesel-generating set. IEEE Transactions on Energy Conversion, 21(2), 476-483. 